Accepted for publication in Applied Physics Letters.

\title{
SWITCHABLE MIRRORS BASED ON NICKEL-MAGNESIUM FILMS
}

\author{
T. J. Richardson ${ }^{(a)}$, J. L. Slack, R. D. Armitage, R. Kostecki, B. Farangis, and M. D. Rubin \\ Building Technologies Department \\ Environmental Energy Technologies Division \\ Ernest Orlando Lawrence Berkeley National Laboratory \\ University of California \\ 1 Cyclotron Road \\ Berkeley, California 94720
}

January 2001 


\title{
SWITCHABLE MIRRORS BASED ON NICKEL-MAGNESIUM FILMS
}

\author{
T. J. Richardson ${ }^{\text {a }}$ J. L. Slack, R. D. Armitage, R. Kostecki, B. Farangis, and M. D. Rubin \\ Environmental Energy Technologies Division, Lawrence Berkeley National Laboratory, \\ Berkeley, California 94720
}

\begin{abstract}
An electrochromic mirror electrode based on reversible uptake of hydrogen in nickel magnesium alloy films is reported. Thin, magnesium-rich $\mathrm{Ni}-\mathrm{Mg}$ films prepared on glass substrates by cosputtering from $\mathrm{Ni}$ and $\mathrm{Mg}$ targets are mirror-like in appearance and have low visible transmittance. Upon exposure to hydrogen gas or on cathodic polarization in alkaline electrolyte, the films take up hydrogen and become transparent. When hydrogen is removed, the mirror properties are recovered. The transition is believed to result from reversible formation of $\mathrm{Mg}_{2} \mathrm{NiH}_{4}$ and $\mathrm{MgH}_{2}$. A thin overlayer of palladium was found to enhance the kinetics of hydrogen insertion and extraction, and to protect the metal surface against oxidation.

Devices capable of switching between mirror and transparent states may find applications in architectural and transportation energy conservation, lighting and displays, aerospace insolation control, and optical communications systems. Switchable mirrors based on rare earth hydrides were discovered by Huiberts et al., ${ }^{1}$ who observed a reversible metal-to-insulator transition when a thin film $(150$ to $500 \mathrm{~nm}$ ) of yttrium or lanthanum coated with a thin layer of palladium was exposed to hydrogen gas. The transition accompanies conversion of a metallic dihydride phase to a semiconducting trihydride. Rare earth-magnesium alloy films ${ }^{2}$ were subsequently found to be superior to the pure lanthanides in maximum transparency and mirror-state reflectivity. Phase separation appears to occur when these alloys take up hydrogen, giving transparent $\mathrm{MgH}_{2}$ and $\mathrm{LnH}_{2-3}$, both of which may participate in the switching mechanism. ${ }^{3}$ Because the rare earths are highly vulnerable to oxidation, a Pd overlayer at least $5 \mathrm{~nm}$ thick is required for films exposed to air or to an alkaline electrolyte. Although the Pd catalyzes the uptake and removal of hydrogen, it limits the maximum transparency of the composite film to about 50\%. The influence of the Pd layer and of a $\mathrm{Pd} / \mathrm{AlO}_{\mathrm{x}}$ composite cap layer on hydrogen uptake by rare earth-based films have been studied extensively by van Gogh et al. ${ }^{5}$ and by van der Molen et al. ${ }^{6}$
\end{abstract}

Among the many transition metals and alloys that have been investigated for use in low pressure hydrogen storage devices or as electrodes in secondary batteries, a few are known to form semiconducting hydride phases such as $\mathrm{Mg}_{2} \mathrm{NiH}_{4},{ }^{7} \mathrm{Mg}_{2} \mathrm{CoH}_{5},{ }^{8}$ and $\mathrm{Mg}_{2} \mathrm{FeH}_{6} .{ }^{9}$ In the case of nickel, a stoichiometric alloy phase, $\mathrm{Mg}_{2} \mathrm{Ni}$, with the same $\mathrm{Mg}-\mathrm{Ni}$ ratio as in the hydride, can be prepared from the elements. In $\mathrm{Mg}_{2} \mathrm{Ni}$ (Fig. 1a), there are $\mathrm{Ni}-\mathrm{Ni}$ bonds (shown as hollow rods), two types of $\mathrm{Ni}-\mathrm{Mg}$ bonds (solid rods) and three types of Mg-Mg bonds (not shown). ${ }^{10}$ The Ni-Ni bonds and $\mathrm{Mg}-\mathrm{Mg}$ bonds are shorter in the alloy than in the pure elements. The alloy absorbs hydrogen without structural rearrangement up to a composition of $\mathrm{Mg}_{2} \mathrm{NiH}_{0.3}{ }^{7}$ This phase has metallic properties similar to those of the pure alloy. Further introduction of hydrogen produces $\mathrm{Mg}_{2} \mathrm{NiH}_{4}$ (Fig. 1b). In this material, ${ }^{11}$ each nickel atom is surrounded by four hydrogen atoms in a tetrahedral array, with short $\mathrm{Ni}-\mathrm{H}$ bond lengths and $\mathrm{Mg}-\mathrm{H}$ bonds slightly longer than those in magnesium hydride

\footnotetext{
a tjrichardson@lbl.gov
} 
$\left(\mathrm{MgH}_{2}\right){ }^{12} \mathrm{No} \mathrm{Ni}-\mathrm{Mg}$ bonds remain. $\mathrm{Mg}_{2} \mathrm{NiH}_{4}$ is a red solid. ${ }^{7}$ Its optical bandgap has been reported variously as $2.0,{ }^{13} 1.9,{ }^{14} 1.7^{15} \mathrm{eV}$ for bulk samples, and $1.3 \mathrm{eV}$ for an Ni-Mg-H film of unknown composition. ${ }^{16} \mathrm{MgH}_{2}$ is a colorless insulator, $\mathrm{E}_{\mathrm{g}}=5.16 \mathrm{eV} .{ }^{17}$ Although the bulk hydrides are generally prepared at elevated temperature and pressure, the $\mathrm{H}_{2}$ dissociation pressures at $25^{\circ} \mathrm{C}$ are ca. $1 \times 10^{-5}$ atm for $\mathrm{Mg}_{2} \mathrm{NiH}_{4}{ }^{7}$ and $1 \times 10^{-6}$ atm for $\mathrm{MgH}_{2}{ }^{18}$

$\mathrm{Ni}-\mathrm{Mg}$ films were deposited by $\mathrm{DC}$ magnetron co-sputtering from 2 in diameter $\mathrm{Ni}$ and $\mathrm{Mg}$ $(99.98 \%)$ targets onto glass substrates with and without transparent conductive coatings. The base pressure was $1.4 \times 10^{-7}$ Torr, process pressure 2 mTorr, Ni power $20 \mathrm{~W}$, Mg power $22 \mathrm{~W}$, target-tosubstrate distance $7.5 \mathrm{~cm}$. Deposition rates ranged from 0.33 to $0.55 \mathrm{~nm} / \mathrm{s}$, depending on location of the substrate in the horizontal plane over the sputter sources. When used, the Pd over-layer was applied at 10 mTorr, Pd power 12.4 watts, deposition rate $0.16 \mathrm{~nm} / \mathrm{s}$. Film thicknesses were measured by stylus profilometry. Samples for mid-IR spectroscopy were deposited on highresistivity silicon discs and measured by reflectance at $45^{\circ}$ through the silicon substrates. Samples for Raman spectroscopy were prepared on $0.1 \mathrm{~mm}$ thick glass to minimize substrate contributions to the spectra.

Switching from the as-deposited mirror state to the transparent state was achieved by exposing the films to a dry gas stream containing $4 \%$ hydrogen in argon or helium. The mirror state was recovered by exposing the films to ambient air. Electrochemical switching was carried out in aqueous alkaline electrolyte (5-8 $\mathrm{M} \mathrm{KOH}, \mathrm{Pt}$ counter electrode, $\mathrm{HgO} / \mathrm{Hg}$ reference), with in situ measurement of optical transmission spectra or photopic transmittance. Film compositions were determined by Rutherford backscattering spectrometry (RBS) and particle induced x-ray emission (PIXE).

The freshly deposited Ni-Mg films were amorphous by X-ray diffraction (XRD), showing only weak reflections due to $\mathrm{Pd}$. After annealing in dry nitrogen at $125^{\circ} \mathrm{C}, \mathrm{Mg}_{2} \mathrm{Ni}, \mathrm{Mg}$, and $\mathrm{Mg}_{6} \mathrm{Pd}$ were present. The annealed films did not take up hydrogen readily, and no changes were observed in the XRD pattern obtained under a stream of $4 \% \mathrm{H}_{2}$. All Ni-Mg films were highly reflecting (Fig. 2) and had very low transmittance (Fig. 3). The transition speed and maximum transmittance depended upon the $\mathrm{Ni}$ to $\mathrm{Mg}$ ratio (see below). Films without a Pd overlayer switched very slowly and less completely. Gasochromic switching times of less than $10 \mathrm{~s}$ were achieved. Cosputtering from offset sources produced films with position-dependent $\mathrm{Ni}-\mathrm{Mg}$ atomic ratios. RBS-PIXE analysis showed that areas with $\mathrm{Mg}: \mathrm{Ni}$ atomic ratios between 4.5:1 and 7:1 became transparent on the first exposure to $\mathrm{H}_{2}$. On subsequent hydriding following air oxidation, the area of switching expanded to include $\mathrm{Mg}$ :Ni ratios from 3.5:1 to 10:1. The color of thick transparent films varied from pale yellow in $\mathrm{Mg}-$ rich regions to deep red in Ni-rich areas. The absorption edge of $\mathrm{Mg}_{2} \mathrm{NiH}_{4}$ is shifted to shorter wavelengths by the presence of $\mathrm{MgH}_{2}$, as in the case of rare earth-Mg hydride mixtures. ${ }^{2}$ The estimated optical bandgap varied from $2.8 \mathrm{eV}$ for films containing a large excess of $\mathrm{Mg}$ to about 2.5 $\mathrm{eV}$ for $\mathrm{Mg}: \mathrm{Ni} \approx 4$.

Electrochemical hydrogen loading produced similar switching between mirror and transparent states (Fig. 4). Only a broad reduction feature beginning at $-0.8 \mathrm{~V}$, accompanied by a small increase in transmittance is observed before the onset of hydrogen evolution at around $-1.0 \mathrm{~V}$, when the film rapidly becomes clear. A small anodic peak centered at $-0.6 \mathrm{~V}$, and probably due to hydrogen desorption form the $\mathrm{Pd}$ overlayer, signals the onset of the return to the metallic state, a somewhat slower process than hydrogen uptake. The anodic current peaks at $-0.3 \mathrm{~V}$, with complete recovery 
of the mirror-like appearance. The charge passed during the anodic sweep is $61 \mathrm{mC} / \mathrm{cm}^{2}$. The theoretical capacities of $\mathrm{Mg}$ and $\mathrm{Mg}_{2} \mathrm{Ni}$ are 1.38 and $1.24 \mathrm{mC} / \mathrm{nm}-\mathrm{cm}^{2}$. Since the Pd layer can account for no more than about $10 \mathrm{mC} / \mathrm{cm}^{2}$, the Ni-Mg capacity is that expected for a 37 to $41 \mathrm{~nm}$ thickness, depending on Ni-Mg ratio, consistent with the measured thickness of $50 \mathrm{~nm}$ and allowing for some porosity. Switching to the clear state in $40 \mathrm{~s}$ and to the mirror state in $90 \mathrm{~s}$ could be achieved by stepping the potential to $-1.2 \mathrm{~V}$ and $-0.2 \mathrm{~V}$, respectively.

The presence of $\mathrm{Mg}_{2} \mathrm{NiH}_{4}$ in the transparent films is supported by vibrational spectroscopy (Fig. 5). The Raman peak at about $1650 \mathrm{~cm}^{-1}$ and the infrared absorption maximum at $1600 \mathrm{~cm}^{-1}$ are attributed to $v_{1}$ and $v_{3}$ of the tetrahedral $\mathrm{NiH}_{4}{ }^{4-}$ unit. While all four vibrational modes of a regular tetrahedron are Raman active, the symmetric stretching mode, $v_{1}$, generally has the highest intensity, and is similar in frequency to the stronger of the two IR absorption modes, $v_{3}$. No Raman spectrum has been reported for $\mathrm{Mg}_{2} \mathrm{NiH}_{4}$. In the isoelectronic species, $\mathrm{AsH}_{4}{ }^{+}$and $\mathrm{GaH}_{4}{ }^{-}, \mathrm{v}_{1}$ appears at 2080 and $1807 \mathrm{~cm}^{-1}$, respectively. ${ }^{19}$ The stretching frequencies decrease with decreasing charge on the central atom (zero in the case of $\mathrm{NiH}_{4}{ }^{4-}$ ) and are lowered by hydrogen bonding, ${ }^{19}$ which is pronounced in $\mathrm{Mg}_{2} \mathrm{NiH}_{4}$. An infrared absorption at $1638 \mathrm{~cm}^{-1}$ has been reported for bulk $\mathrm{Mg}_{2} \mathrm{NiH}_{4}{ }^{20}$ The other prominent feature in the infrared spectrum of the hydrided film is a broad absorption centered around $1000 \mathrm{~cm}^{-1}$. This peak is stronger relative to that of $\mathrm{Mg}_{2} \mathrm{NiH}_{4}$ (the baseline also varies with $\mathrm{Ni}: \mathrm{Mg}$ ratio) in regions of the film with higher Mg content (Fig. 5(d), and is assigned to $\mathrm{MgH}_{2}{ }^{21}$ All absorption features disappear when hydrogen is removed from the film, and reappear when it is loaded again with hydrogen.

Hydrogen uptake by pure $\mathrm{Mg}$ is slow at ambient temperature and is kinetically hindered by formation of a dense surface layer of $\mathrm{MgH}_{2} \cdot{ }^{22,23}$ The rate is increased by the presence of nickel ${ }^{24,25}$ or oxide ${ }^{26}$ on the Mg surface, or by decreased crystallinity. ${ }^{27}$ We observed faster switching in film areas with higher nickel content, and gradual improvement with time and switching cycle, especially in the more $\mathrm{Mg}$-rich regions. The latter may be due to alloying of unreacted $\mathrm{Ni}$ and $\mathrm{Mg}$, or to surface oxidation caused by disruption of the Pd coating during cycling. Since no transparent binary hydride of nickel is known, it is clear that a nickel magnesium hydride $\left(\mathrm{Mg}_{2} \mathrm{NiH}_{4}\right)$ must participate in the switching phenomenon. Formation of $\mathrm{Mg}_{2} \mathrm{NiH}_{4}$ or $\mathrm{MgH}_{2}$ from their metallic precursors results in a volume increase of about $32 \%$ in each case. $\mathrm{Ni}-\mathrm{Mg}$ films on thin glass substrates exhibited significant bending on exposure to hydrogen, while a $1.2 \mu \mathrm{m}$ thick film confined on a rigid substrate was found by profilometry to increase in thickness by $31 \%$. Preliminary results indicate similar switching behavior in cobalt-magnesium films.

In conclusion, a class of switchable mirror based on a transition metal alloy film has been discovered. The rapid, reversible conversion from the highly reflecting metallic state to a transparent semiconducting state is due to formation of known metal hydride phases, and can be produced by either electrochromic or gasochromic means.

\section{Acknowledgment}

The authors thank Dr. Kin Man Yu of LBNL for performing RBS and PIXE measurements. This work was supported by the Assistant Secretary for Energy Efficiency and Renewable Energy, Office of Building Technology, State and Community Programs, Office of Building Research and Standards of the U.S. Department of Energy under Contract No. DE-AC03-76SF00098. 


\section{References}

1. J.N. Huiberts, R. Griessen, J.H. Rector, R.J. Wijngaarden, J.P. Dekker, D.G. de Groot, and N.J. Koeman, Nature 380, 231 (1996).

2. P. van der Sluis, M. Ouwerkerk, and P.A. Duine, Appl. Phys. Lett. 70, 3356 (1997).

3. D. G. Nagengast, A. T. M. van Gogh, E. S. Kooij, B. Dam, and R. Griessen, Appl. Phys. Lett. 75, 2050 (1999).

4. K. von Rottkay, M. Rubin, and P.A. Duine, J. Appl. Phys. 85, 408 (1999).

5. A.T.M. van Gogh, S.J. van der Molen, J.W.J. Kerssemakers, N.J. Koeman, R. Griessen, Appl. Phys. Lett. 77, 815 (2000).

6. S.J. van der Molen, J.W.J. Kerssemakers, J.H. Rector, N.J. Koeman, B. Dam, R. Griessen, J. Appl. Phys. 86, 6107 (1999).

7. J. J. Reilly and R. H. Wiswall, Inorg. Chem. 7, 2254, (1968).

8. P. Zolliker, K. Yvon, P. Fischer, and J. Schefer, Inorg. Chem. 24, 4177, (1985).

9. J. J. Didisheim, P. Zolliker, K. Yvon, P. Fischer, J. Schefer, and M. Gubelmann, Inorg. Chem. 23, 1953, (1984).

10. D. Noreus and P. E. Werner, Acta Chem. Scand. Ser. A 36, 847 (1982).

11. P. Zolliker, K. Yvon, J. D. Jorgensen, and F. J. Rotella, Inorg. Chem. 25, 3590, (1986).

12. W. H. Zachariasen, C. E. Holley, and J. F. Stamper, Acta Crystallogr. 16, 352 (1963).

13. P. Selvam, B. Wiswanathan, and V. Srinivasan, J. Electron Spectrosc. 46, 357 (1988).

14. D. Lupu, R. Grecu, and S. I. Farcas, Z. Phys. Chem. 181, 143 (1993).

15. D. Lupu, R. Sarbu, and A. Biris, Int. J. Hydrogen Energy 12, 425 (1987).

16. Y. Fujita, M. Yamaguchi, and I. Yamamoto, Z. Phys. Chem. 163, 633 (1989).

17. G. Krasko, in Metal-Hydrogen Systems, ed. T. Nejat Veziroglu, (Pergamon, New York, 1982), p. 367.

18. B. Bogdanović, Int. J. Hydrogen Energy 9, 937 (1984).

19. K. Nakamoto, Infrared and Raman Spectra of Inorganic and Coordination Compounds, $4^{\text {th }}$ Ed. (J. Wiley and Sons, New York, 1986), pp. 130-131.

20. N. Huang, H. Yamauchi, J. Wu, and Q. Wang, Z. Phys. Chem. 163, 225 (1989).

21. J. R. Santisteban, G. J. Cuello, J. Davidowski, A. Fainstein, H. A. Peretti, A. Ivanov, and F. J. Bermejo, Phys. Rev. B 62, 37 (2000).

22. J. Ryden, B. Hjörvarsson, T. Ericsson, E. Karlsson, A. Krozer, and B. Kasemo, J. Less-Common Metals 152, 295 (1989).

23. P. Spatz, H. A. Aebischer, A. Krozer, and L. Schlapbach, Z. Phys. Chem. 181, 393 (1993).

24. F. G. Eisenberg, D. A. Zagnoli, and J. J. Sheridan, J. Less-Common Metals 74, 323 (1980).

25. F. Stillesjø, S. Olafsson, B. Hjörvarsson, and E. Karlsson, Z. Phys. Chem. 181, 353 (1993).

26. P. Hjort, A. Krozer, and B. Kasemo, J. Alloys and Compounds 237, 74 (1996).

27. K. Higuchi, H. Kajioka, K. Toiyama, H. Fujii, S. Orimo, and Y. Kikuchi, J. Alloys and Compounds 293-295, 484 (1999). 

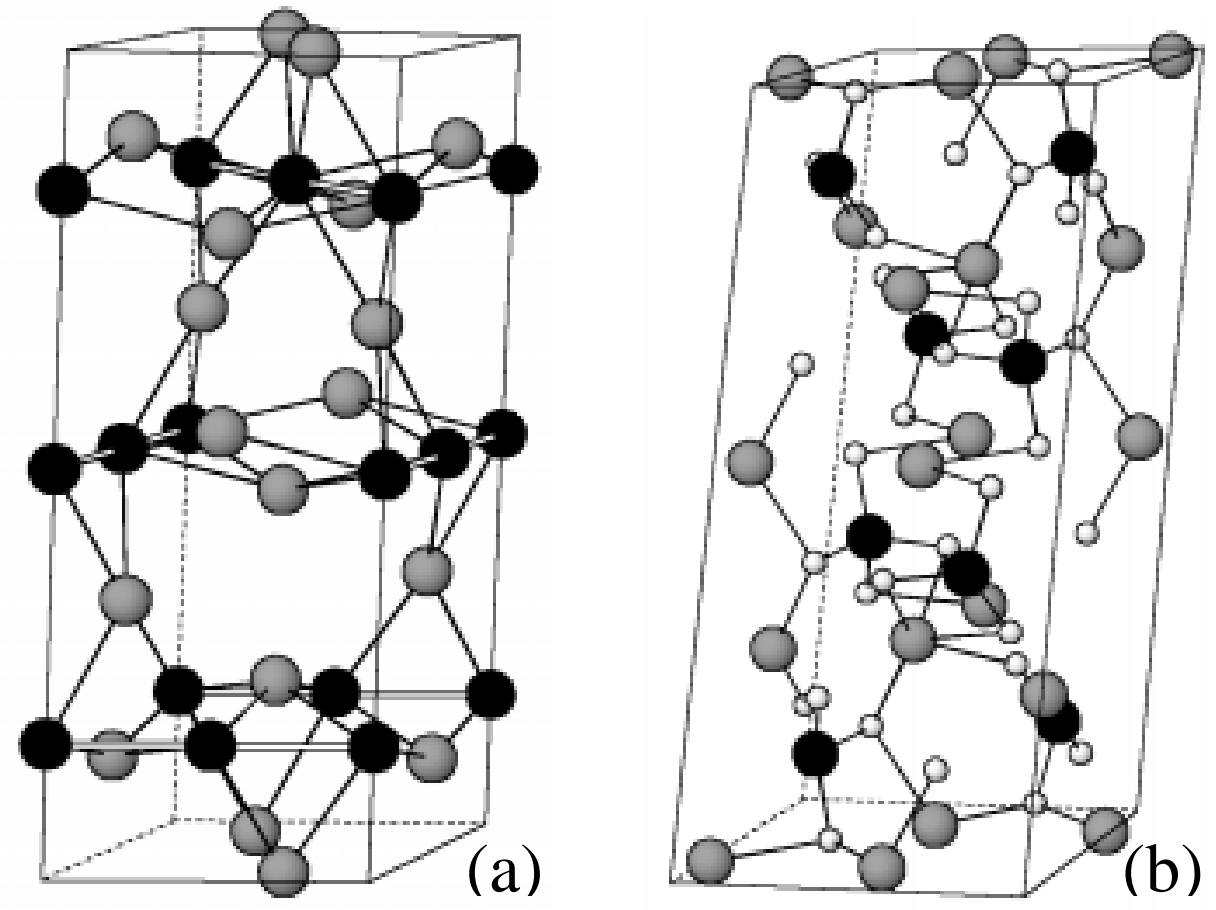

Figure 1. Crystal structures of (a) $\mathrm{Mg}_{2} \mathrm{Ni}$ and (b) $\mathrm{Mg}_{2} \mathrm{NiH}_{4}$. Large black spheres: $\mathrm{Ni}$, large gray spheres: $\mathrm{Mg}$, small spheres: $\mathrm{H}$.

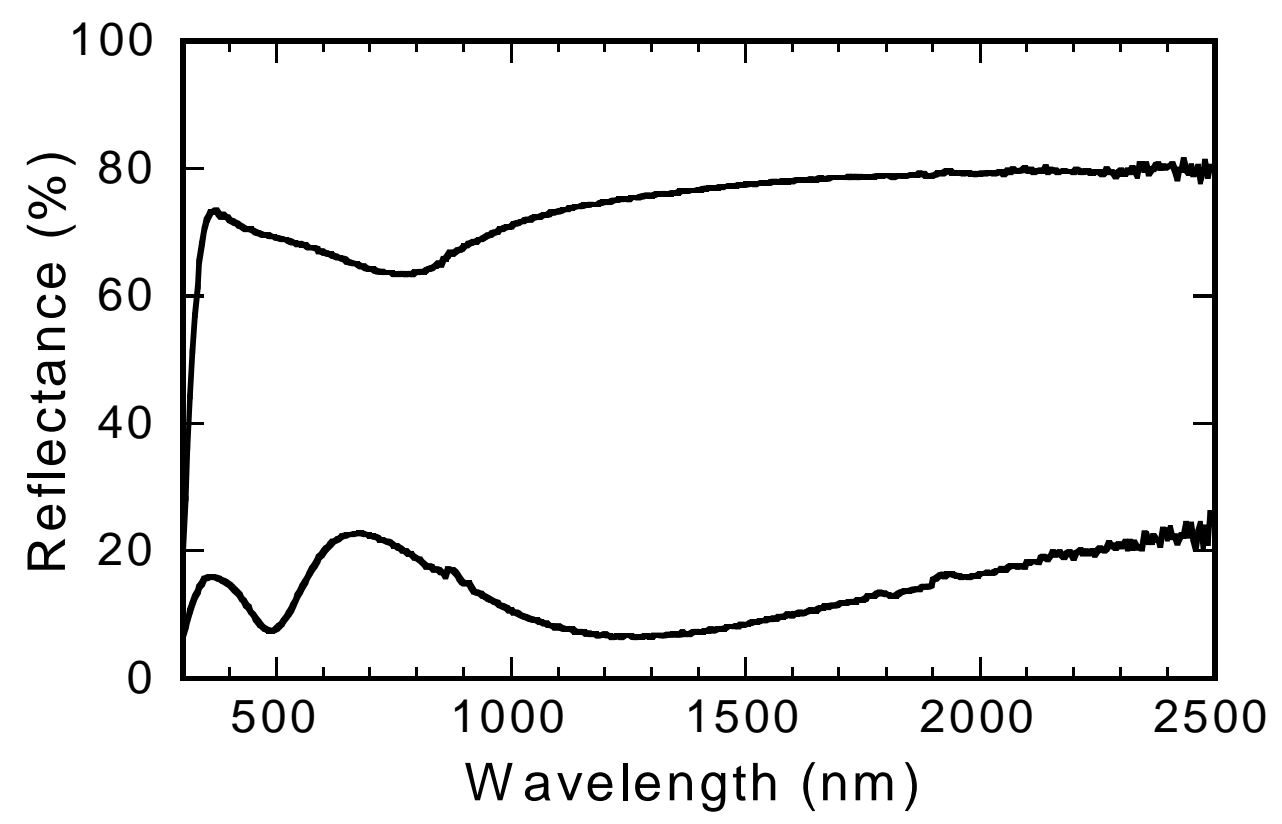

Figure 2. Reflectance spectra of $80 \mathrm{~nm}$ Ni-Mg film with $5 \mathrm{~nm}$ Pd overlayer on glass substrate in the metallic (upper curve) and hydride (lower curve) states. Spectra were recorded from the back (substrate) side. 


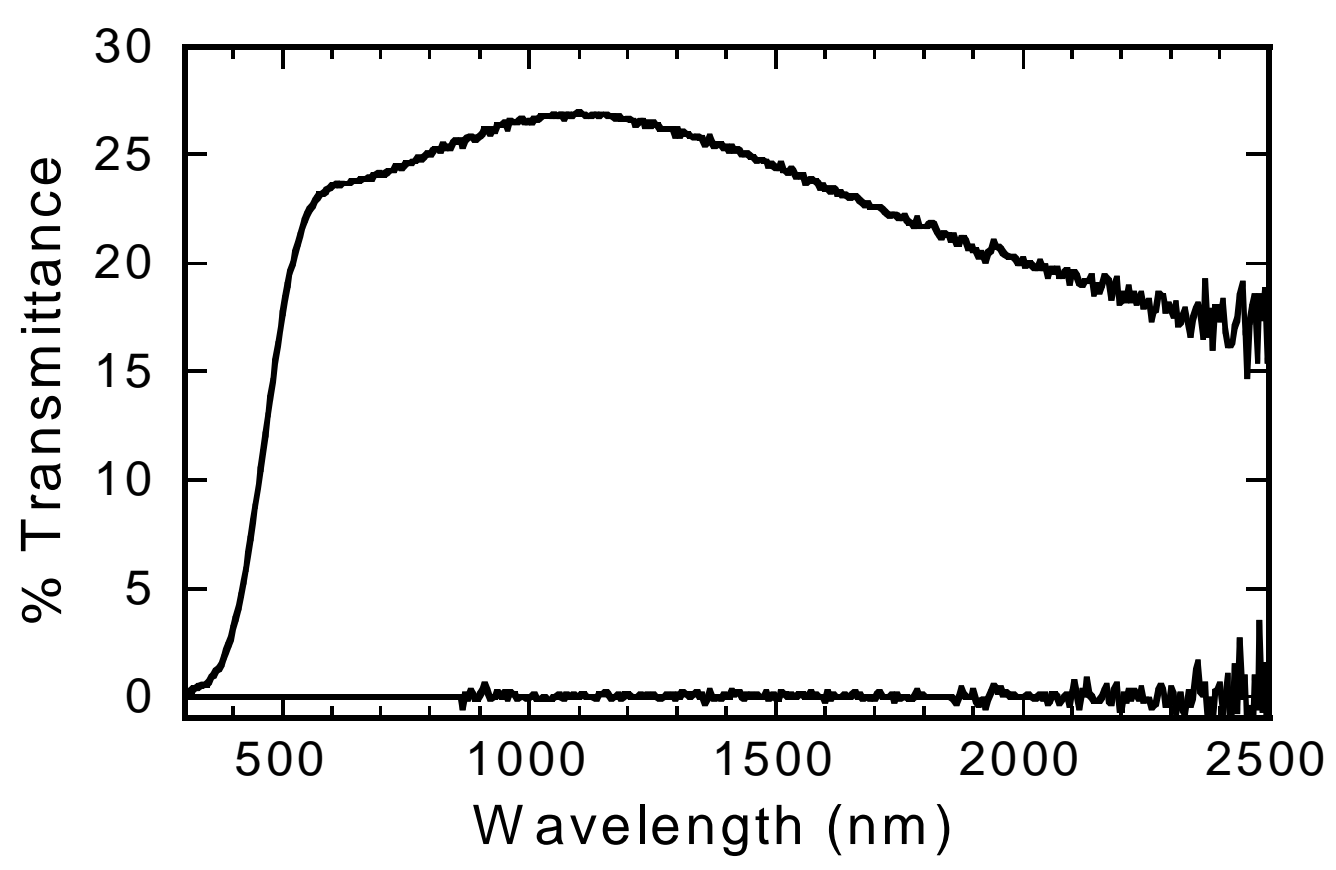

Figure 3. Transmittance spectra of $80 \mathrm{~nm}$ Ni-Mg film with $5 \mathrm{~nm}$ Pd overlayer on glass substrate in metallic (lower curve) and hydride (upper curve) states.

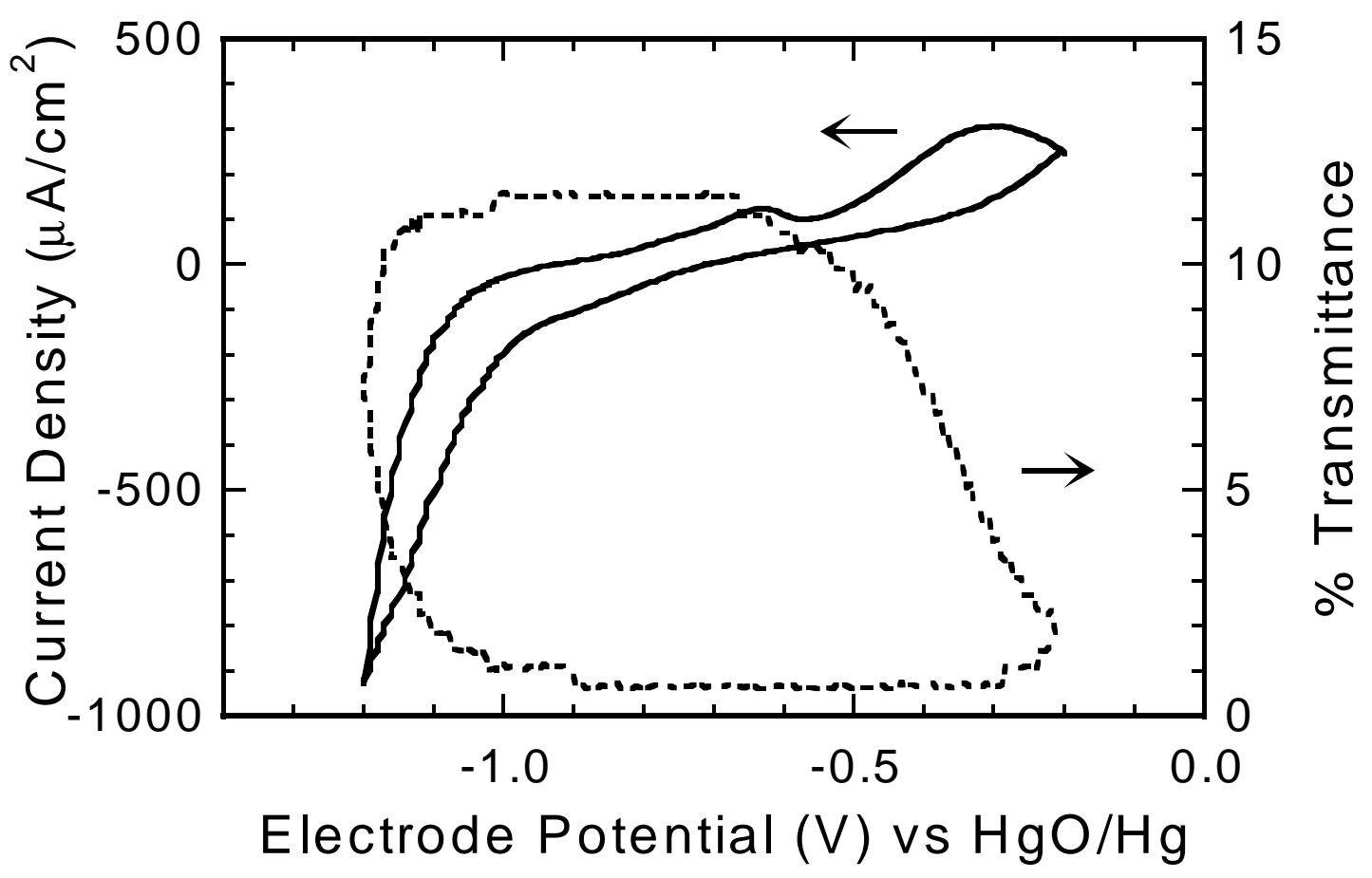

Figure 4. Electrochemical switching (cycle number 4 shown, others are similar) of $50 \mathrm{~nm} \mathrm{Ni}-\mathrm{Mg}$ film with $10 \mathrm{~nm}$ Pd overlayer on ITO glass. Scan rate: $5 \mathrm{mV} / \mathrm{s}$, active area: $5.0 \mathrm{~cm}^{2}$. 


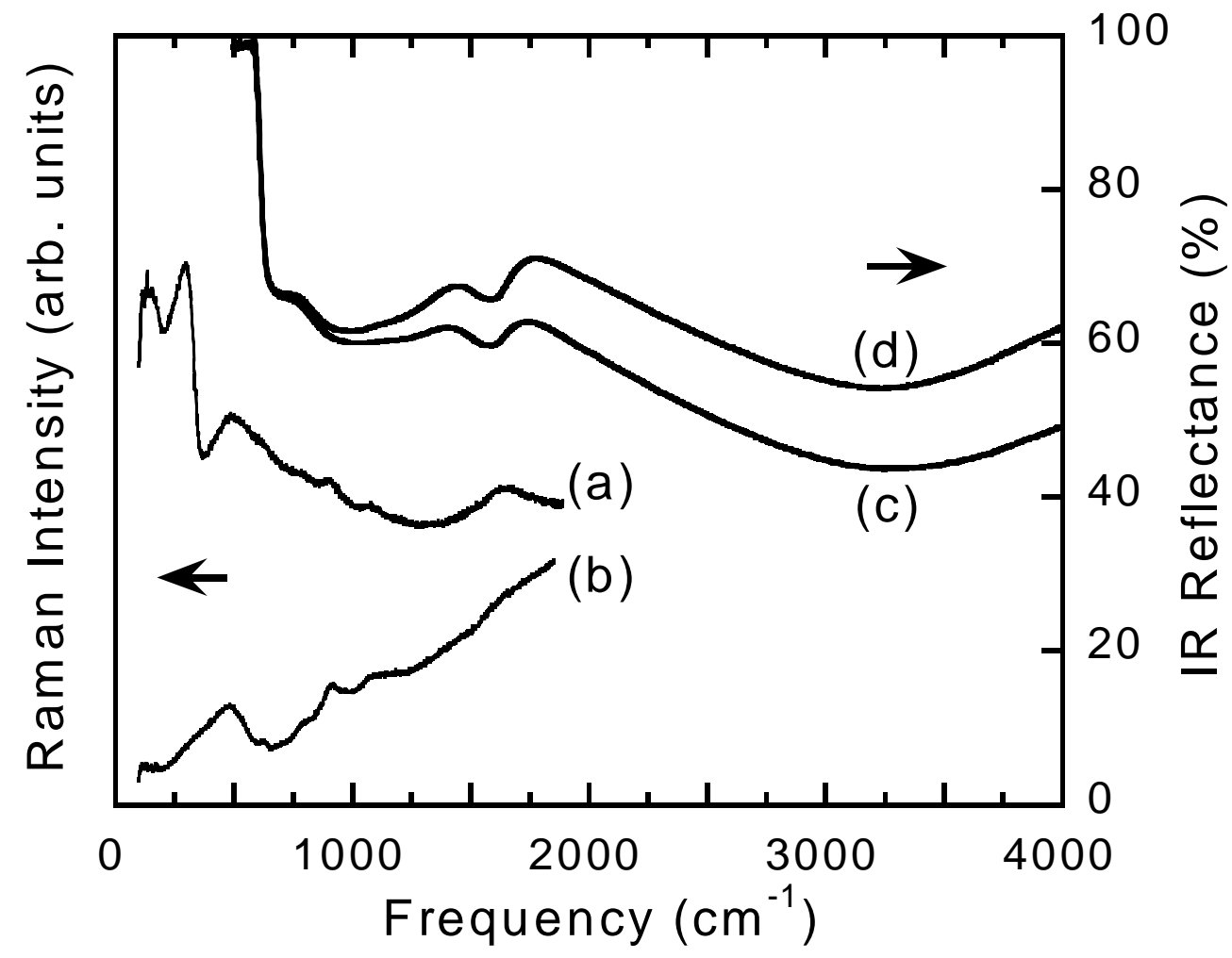

Figure 5. Raman spectra of: (a)1 $\mu \mathrm{m}$ Ni-Mg film on glass in hydride state, obtained from substrate side, and (b) of glass substrate; IR internal reflectance spectra of (c)1 $\mu \mathrm{m} \mathrm{Ni-Mg} \mathrm{film} \mathrm{on} \mathrm{Si}$ in hydride state and (d) as (c) but with higher $\mathrm{Mg} / \mathrm{Ni}$ ratio. 